\title{
Guidance plans for solid waste management during COVID-19 in Makkah, Saudi Arabia
}

\author{
Faisal Osra ${ }^{1} \cdot$ Essam A. Morsy ${ }^{2,3} \cdot$ Ibrahim H.A. Abd El-Rahim ${ }^{2,4}$ \\ Received: 28 March 2021 / Accepted: 14 July 2021 / Published online: 23 July 2021 \\ (C) Saudi Society for Geosciences 2021
}

\begin{abstract}
The COVID-19 pandemic has emphasized disasters related to environmental topics, human health, social lifestyles, and economic systems around the world. COVID-19 may further spread through municipal solid waste (MSW), if it is collected, handled, transported, or disposed in an improper way. The current paper provides an overview of the multiple challenges that COVID-19 has introduced to the various tasks of MSW management including the impact of the implemented precautionary measures on MSW management, priorities and hierarchy of MSW, direct impact on the constitution, and characterization of MSW in Makkah, Saudi Arabia, based on waste management characterization guidance. In addition, specific and alternative guidance plans for the potential critical points of the infection were suggested to protect public health during the pandemic. The results of the current study revealed that the hierarchical system of MSW was modified under pandemic conditions. Implementation of control measures in Makkah has led to a change of lifestyle, which resulted in a physical change of the MSW constitution in Makkah, with the following average rates: organic matter, 57\%; plastics, 31\%; paper and cardboard, 9\%; metals, $1 \%$; glass, $1 \%$; and wood, $1 \%$. In conclusion, a specific guidance plan for MSW management during the COVID-19 pandemic was developed, aimed at handlers, pickers, collection, transportation, transfer stations, and MSW disposal. Such a guidance plan may play a vital role in controlling the pandemic, especially in the outdoor environment. The suggested guidance plan describes and specifies structured and ordered practices of MSW management in Makkah during COVID-19 and other pandemics.
\end{abstract}

Keywords COVID-19 $\cdot$ Guidance plan $\cdot$ Municipal solid waste $\cdot$ Makkah $\cdot$ Saudi Arabia

\section{Introduction}

By the end of 2019, an exceptionally high number of pneumonia cases with unusual characteristics had been detected in

Responsible Editor: Amjad Kallel

Ibrahim H.A. Abd El-Rahim

ihabdelrahim@uqu.edu.sa

Faisal Osra

faosra@uqu.edu.sa

1 Civil Engineering Department, College of Engineering and Islamic Architecture, Umm Al-Qura University, Makkah, Saudi Arabia

2 Department of Environmental and Health Research, Umm Al-Qura University, P.O. Box 6287, Makkah 21955, Saudi Arabia

3 Geophysics Department, Faculty of Science, Cairo University, Giza, Egypt

4 Infectious Diseases, Department of Animal Medicine, Faculty of Veterinary Medicine, Assiut University, Assiut 71526, Egypt the capital of Hubei province, China (Wuhan), as the result of a novel infectious coronavirus disease (Zhu et al. 2020). This disease is now known as coronavirus disease 2019 (COVID19). Global lockdowns were implemented, to reduce the public SARS-CoV-2 infection risk (Saadat et al. 2020).

Until the 20th of June 2021, the number of the global confirmed cases was 178,268,289 and the number of global deaths was $3,861,485$, while on the local level, the number of infected cases in Saudi Arabia was 474,191 with 7,677 deaths (Johns Hopkins University Coronavirus Resource Centre 2021). In the western region of Saudi Arabia (Makkah and Madinah cities), it was indicated that almost all SARS-CoV-2 infection occurs among the households within the indoor environment (Habeebullah et al. 2021).

Waste management planning requires reliable information about waste generation and its affecting factors as well as forecasts of waste quantities based on evidences (Mazzanti and Zoboli 2008). For decreasing the environmental impacts of waste management, the prevention plan and the treatment 
methods should be based on the waste features produced in a specific area (Zorpas et al. 2015).

The efficient SW management strategy results in great advantages for the waste management guidelines (strategy) and eco-friendly waste management practices including a minimized environmental footprint, enhanced relations with stakeholders, minimized liabilities and environmental risk, and health and safety benefits (Ball and Taleb 2010; Loizia et al. 2018; Zorpas et al. 2014). Strategy development in the framework of waste management aims to increase quality of life and should reduce the impact of several processes on the surrounding environment (Zorpas 2020). Key performance indicators (KPIs) such as the waste compositional analysis, waste recycling and waste accumulation index, prevention activities, and awareness activities were used to measure the environmental performance level in an area, in the framework of waste strategy development (Loizia et al. 2021a). Improvement of coastal environment was detected during COVID-19 lockdown according to the applied KPIs such as waste accumulation index (WAI) and waste accumulation rate (WAR) (Loizia et al. 2021b).

During the COVID-19 pandemic, routine people activities were overturned, which led to a shifting in the trends of solid waste created by medical facilities, quarantine centers, streets, and households (Tripathi et al. 2020). The key concerns for MSW management during the COVID-19 pandemic are the long half-life of SARS-CoV-2 on waste containers and plastic bags resulting in the potential risk of disease spreading through contaminated waste surfaces (Nghiem et al. 2020). Improper management of plastic waste during the COVID19 crises may lead to negative impacts on the environment, animals, and human health (Khoo et al. 2021).

The spread of COVID-19 infection increased and, as a result, severe concerns were concluded in several scientific references (Warnes et al. 2015; Kampf et al. 2020; Luca et al. 2020; and van Doremalen et al. 2020), which indicated that COVID-19 could remain on different surfaces for different periods of time, summarized as follows: $3 \mathrm{~h}$ in aerosols, $72 \mathrm{~h}$ on plastics, $48 \mathrm{~h}$ on steel surfaces, $4 \mathrm{~h}$ on copper, and $24 \mathrm{~h}$ on cardboard. This led to fear regarding the possible spread of infection through MSW collection, transportation, and disposal systems. Das et al. (2021) stated that SARS-CoV-2 can be easily and rapidly transmitted and spread out through municipal solid waste.

Some studies have focused on MSW management during the COVID-19 pandemic, but it is expected that municipalities will have more concerns by the time to control this factor of infection (Smart Waste Report European Union 2020), due to the direct contact between the MSW and the operators (scavengers). It was also indicated that there are direct and indirect preliminary impacts of the COVID-19 pandemic on SW management (Kulkarni and Anantharama 2020; Zand and Heir 2020; Das et al. 2021; Hantoko et al. 2021; Yousefi et al.
2021). Furthermore, the WHO has introduced a specific plan for the treatment and disposal of MSW in medical facilities, by using thermal treatment or effective biocidal agents for destroying SARS-CoV-2 (Kampf et al. 2020). Klemes et al. (2020) summarized the management practices of plastic waste due to the effect of the COVID-19, investigated the options for plastic waste management, and proposed specific guidelines for MSW handling, i.e., changing the consumers' habits during the COVID-19 crisis will modify the priorities of MSW management. Nghiem et al. (2020) inspected the impact of the COVID-19 crisis on MSW and sewage treatment plants, as well as the potential risk of the virus spreading via the nonmedical waste from medical facilities.

Experimentally, infectious SARS-CoV-2 could be detected on day 7 on the external layer of a face mask (Chin et al. 2020). It has been revealed that SARS-CoV-2 can survive on various kinds of surfaces, for $2 \mathrm{~h}$ up to 9 days, such as plastic, steel, PVC, aluminum, metal, wood, ceramic, Teflon, and glass (Kampf et al. 2020), as well as paper/cardboard (Duan et al. 2003) and latex gloves and gowns (Lai et al. 2005; Sizun et al. 2000). A literature survey indicated the potential of spread of the COVID-19 pandemic because of the different tasks (e.g., handling, collection, transportation, and disposal) involving MSW, through improper and traditional environmental management (Mol and Caldas 2020).

The mismanagement of municipal solid waste during the COVID-19 pandemic may lead to many environmental and health problems, especially in the outdoor environment, such as viral environmental contamination and facilitating disease transmission. The uncontrollable spread of personal protective equipment (PPE) from infected and uninfected individuals may increase the potential of COVID-19 spread, due to the mixing of infected with uninfected MSW. The present study reviews MSW management practices in the pre-pandemic conditions of Makkah, as well as during the COVID-19 pandemic. We aimed to characterize the MSW generated in Makkah during the lockdown due to the COVID-19 pandemic, which has influenced the existing MSW management practices. This study also contributes by providing an optimal and specific guideline for handling, collecting, transporting, and disposing of MSW.

\section{Materials and methods}

The impacts of COVID-19 on both implemented actions on MSW in Makkah and on the hierarchy of MSW management were investigated. The generation of MSW from commercial centers, educational facilities, wedding halls, hotels, visitor housing, restaurants, and cafes was decreased. MSW characterization in Makkah was discussed before and during the COVID-19 lockdown on a daily basis and sorted in situ households and ended with the proposed MSW guidance plans. 
Table 1 Implemented actions of Saudi authorities during the COVID-19 pandemic and their impacts on MSW

\begin{tabular}{|c|c|c|c|}
\hline No. & Date & Implemented action & $\begin{array}{l}\text { Direct/indirect impact on municipal solid waste } \\
\text { management (MSWM) }\end{array}$ \\
\hline 1 & $\begin{array}{l}\text { 26th } \\
\qquad \text { Fe- } \\
\text { b. } 2020\end{array}$ & $\begin{array}{l}\text { - Suspending entry to the Kingdom for Umrah, visiting and tourist visas, and } \\
\text { mobility with national identity among citizens of the Gulf Cooperation } \\
\text { Council countries }\end{array}$ & $\begin{array}{l}\text { - Decreasing Umrah performers and decreasing } \\
\text { the generation of MSW in Makkah }\end{array}$ \\
\hline 2 & $\begin{array}{l}\text { 4th } \\
\text { Marc- } \\
\text { h } 2020\end{array}$ & - Suspending the performance of Umrah inside the Kingdom & - Decreasing the generation of MSW in Makkah \\
\hline 3 & $\begin{array}{l}\text { 8th } \\
\text { Marc- } \\
\text { h } 2020\end{array}$ & $\begin{array}{l}\text { - Suspending studies in all schools and universities in the Kingdom of Saudi } \\
\text { Arabia (KSA) }\end{array}$ & $\begin{array}{l}\text { - Decreasing the generation of MSW from } \\
\text { schools and universities }\end{array}$ \\
\hline 4 & $\begin{array}{l}\text { 12th } \\
\text { Marc- } \\
\text { h } 2020\end{array}$ & - Suspending events in wedding halls, lounges, and hotels & $\begin{array}{l}\text { - Decreasing the generated MSW from weddings } \\
\text { and hotels }\end{array}$ \\
\hline 5 & $\begin{array}{l}\text { 14th } \\
\text { Marc- } \\
\text { h } 2020\end{array}$ & - Suspension of international flights for 2 weeks & $\begin{array}{l}\text { - Changing lifestyle will change the status of } \\
\text { MSW }\end{array}$ \\
\hline 7 & $\begin{array}{l}\text { 15th } \\
\text { Marc- } \\
\text { h } 2020\end{array}$ & $\begin{array}{l}\text { - Temporarily suspending marine trips, except for goods, between the Kingdom } \\
\text { and several countries }\end{array}$ & - Changing the status of consumables and MSW \\
\hline 8 & $\begin{array}{l}\text { 16th } \\
\text { Marc- } \\
\text { h } 2020\end{array}$ & $\begin{array}{l}\text { - Suspending attendance at workplaces in government agencies } \\
\text { - Close markets and commercial complexes } \\
\text { - Service in restaurants and cafes is limited to external requests. } \\
\text { - Reducing the presence of beneficiaries in government departments } \\
\text { - Promote remote work }\end{array}$ & $\begin{array}{l}\text { - The generated MSW from commercial centers } \\
\text { will be decreased. } \\
\text { - The generated MSW from restaurants and cafes } \\
\text { will be decreased. }\end{array}$ \\
\hline 9 & $\begin{array}{l}\text { 17th } \\
\text { Marc- } \\
\text { h } 2020\end{array}$ & $\begin{array}{l}\text { - Preventing gatherings in public places } \\
\text { - Preventing congregational prayers in mosques, except for the Two Holy } \\
\text { Mosques } \\
\text { - Suspending prayer and being in the two holy mosques, especially on Fridays }\end{array}$ & $\begin{array}{l}\text { - Decreasing the generation of plastic cups and } \\
\text { water bottles from mosques }\end{array}$ \\
\hline 10 & $\begin{array}{l}\text { 20th } \\
\qquad \text { Marc- } \\
\text { h } 2020\end{array}$ & - Suspension of domestic flights, buses, taxis, and trains for a period of 2 weeks & $\begin{array}{l}\text { - Changing lifestyle will change the status of the } \\
\text { generated MSW. }\end{array}$ \\
\hline 11 & $\begin{array}{l}\text { 22nd } \\
\text { Marc- } \\
\text { h } 2020\end{array}$ & - A royal order imposing a curfew from 7 pm until 6 am for 21 days & \\
\hline 12 & $\begin{array}{l}\text { 25th } \\
\qquad \text { Marc- } \\
\text { h } 2020\end{array}$ & - Preventing the residents of the regions from leaving their areas & \\
\hline 13 & $\begin{array}{l}\text { 2nd April } \\
2020\end{array}$ & $\begin{array}{l}\text { - Curfew is imposed throughout all cities of Makkah and Madinah for a period of } \\
24 \mathrm{~h} \text { a day, until further notice. }\end{array}$ & \\
\hline 14 & $\begin{array}{l}\text { 4th April } \\
2020\end{array}$ & $\begin{array}{l}\text { - Implementing additional health precautionary measures in several residential } \\
\text { districts in Jeddah, by preventing entry to or exit from them and curfew in } \\
\text { them over a } 24 \text {-h period }\end{array}$ & \\
\hline 15 & $\begin{array}{l}\text { 5th April } \\
2020\end{array}$ & $\begin{array}{l}\text { - Starting the travel procedures for Umrah performers who are late to leave from } \\
\text { King Abdulaziz international Airport in Jeddah }\end{array}$ & $\begin{array}{l}\text { - Closing of the hotels and housing of Umrah } \\
\text { performers will decrease the associated MSW. }\end{array}$ \\
\hline 16 & $\begin{array}{l}\text { 21st } \\
\text { Jun- } \\
\text { e } 2020\end{array}$ & $\begin{array}{l}\text { - Back to normal life in all regions and cities of the KSA as before the curfew } \\
\text { period, except for Makkah, with full compliance with preventive health } \\
\text { instructions and social distancing }\end{array}$ & $\begin{array}{l}\text { - Gradually moving back to the normal } \\
\text { management system of MSW }\end{array}$ \\
\hline 17 & $\begin{array}{l}\text { 4th } \\
\text { Sep- } \\
\text { t. } 2020\end{array}$ & - Back to normal life in Makkah City & $\begin{array}{l}\text { - Gradually moving back to the normal } \\
\text { management system of MSW }\end{array}$ \\
\hline
\end{tabular}

\section{2-1. Impacts of COVID-19 implemented actions on MSW in Makkah}

In Saudi Arabia, the COVID-19 pandemic is part of the worldwide pandemic. The first SARS-CoV-2 infected case was confirmed by the Saudi Ministry of Health on 2
March 2020. The first positive case was reported in Makkah on the 10th of March 2020. On 21 March 2020, KSA announced the suspension of all domestic and international travel. During the period of 8 March to 4 September 2020, a lockdown was implemented by the Saudi government, as a result of the COVID-19 outbreak, in most of the cities of the 
Kingdom, especially residences in Makkah, and a series of decisions were published through TV channels and social media platforms. After imposing of curfew and lockdown, the number of daily SARS-CoV-2 confirmed cases reduced gradually. On June 21, curfews were lifted through a three-phase program enacted throughout the country, except Makkah city (MoM 2020). These implemented actions and curfew lead to a direct/indirect impact on the status of MSW, regarding the generation rates, characterization, and disposal of MSW as described in Table 1, wherein the generated MSW from commercial centers, schools, universities, wedding halls, hotels, visitors housing, restaurants, and cafes was decreased, in addition to decreasing of the generation of plastic cups and water bottles from mosques.

\section{Impact of the COVID-19 pandemic on the hierarchy of MSW management}

The current research paper discussed the global hierarchy system of MSW management according to the priorities (reduce, reuse, recycle, recover, and disposal) and recommendations of all the related agencies (ISWA 2020; OSHA 2020). The priorities were also discussed during the COVID-19 pandemic.

\section{MSW characterization in Makkah}

MSW was sampled and characterized in different locations in Makkah city during the month of July 2020 (during pandemic and lockdown), for a total of 8 samples (the number of samples was limited due to the pandemic circumstances and lockdown in Makkah). The pandemic-stage components of MSW were compared to those in pre-pandemic conditions.

MSW samples were collected on a daily basis in households, sorted in situ according to the major categories, and weighed and averaged from a total of 8 households of central districts in Makkah city during a week period. All MSW samples weighed in a range of 4-12 Kg, based on waste management characterization guidance (EPA 2002). Selected representative households were planned to, emptied plastic bag every morning, and sorted in situ due to the conditions of the COVID-19 pandemic.

\section{Impact of the lockdown on the generation of MSW in Makkah}

Impact of the lockdown and curfew on the generation of MSW in Makkah was discussed with special reference to the handling of COVID-19 protective tools.

\section{The proposed MSW guidance plans}

Optimizing specific guidance plans for MSW management in Makkah, including collection, transportation, and disposal, during COVID-19 and other future pandemics were suggested, to avoid the spread of COVID-19 through different procedures of MSW management.

\section{Results}

The findings of the current study revealed that the hierarchical system of MSW was modified under the pandemic conditions, where organic and plastic components were increased, and paper/cardboard and glass components were decreased as well as the high potential risk of COVID-19 during MSW handling collection, transportation, and disposal. Finally, the practices of MSW management during the COVID-19 pandemic in Makkah were suggested. This guidance plan describes and specifies structured and ordered practices of MSW management in Makkah during COVID-19 and other pandemics.

\section{Impact of the COVID-19 pandemic on the hierarchy of MSW management}

Globally, according to the ISWA (2020) and OSHA (2020), the suspension of hundreds of waste recycling companies was recommended during the COVID-19 pandemic. The "reduce" concept cannot be applied during the pandemic due to the increase in organic waste as a direct result of people working and studying at their homes. The concept of "reuse" is practically impossible to apply during the pandemic, in terms of minimizing the potential of infection in indoor and outdoor environments. Consequently, the generated MSW quantities serve to pressurize the load on disposal sites (e.g., landfills). All these factors will have led, by the end, to modifying the hierarchical system of MSW, which must be changed under the pandemic conditions (Figure 1). Thus, a vital point of research that must be investigated is how to optimize the most suitable hierarchical system for MSW during the COVID-19 pandemic and future pandemics.

\section{MSW characterization in Makkah before and during the COVID-19 pandemic}

By comparing the MSW characterization in Makkah in prepandemic and during COVID-19 pandemic conditions, we observed an increase in organic and plastic components and a decrease of paper/cardboard and glass components, which can be interpreted as due to the changes in lifestyle and food purchasing requirements, more than the needs, of citizens.

Our findings revealed that the pre-pandemic rates of classification for the collected fourteen solid waste samples, as average rates, were as follows: organic matters, $48 \%$; plastics, $25 \%$; paper and cardboard, $20 \%$; metals, $4 \%$; glass, $2 \%$; textiles, $1 \%$; and wood, $1 \%$. During the COVID-19 lockdown, a field characterization study was conducted using a total of 
Figure 1 Impact of COVID-19 pandemic on hierarchy of MSW management

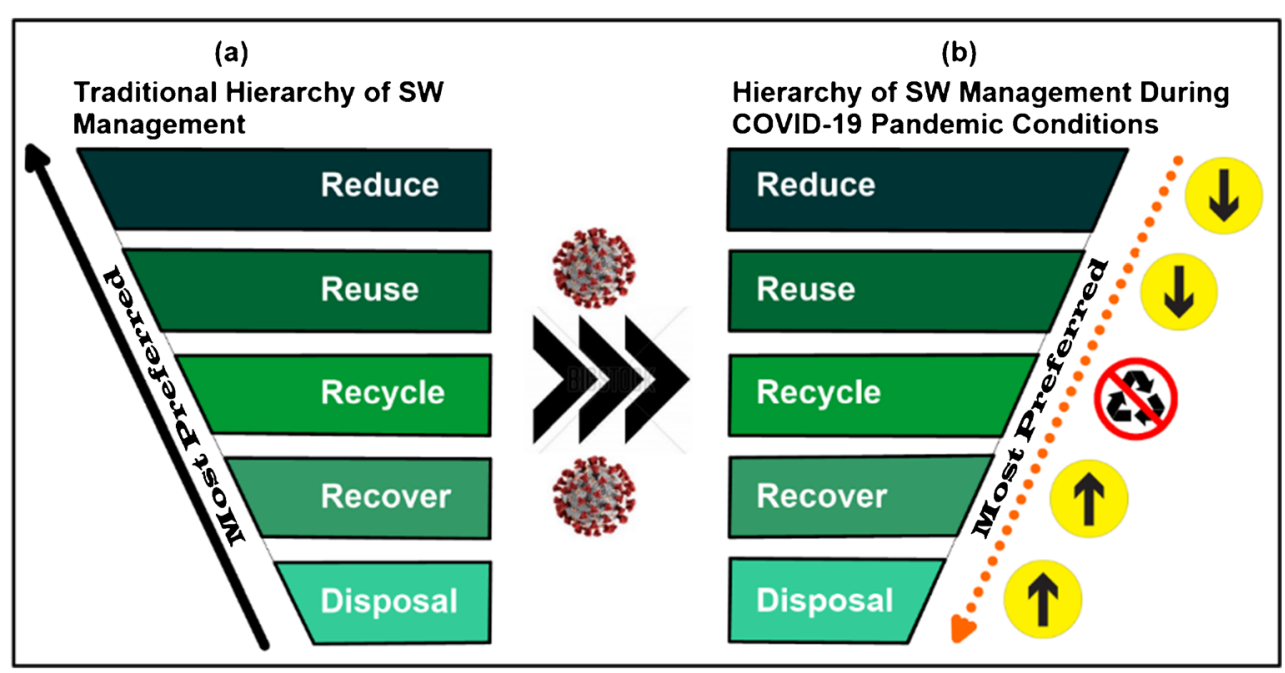

eight samples, with a weight ranging between 22 and $47 \mathrm{Kg}$, for a group of households distributed in the central districts in Makkah, in order to assess the rates of main MSW components; this indicated the average rates of classification as follows: organic matters, 57\%; plastics, 31\%; paper and cardboard, 9\%; metals, 1\%; glass, $1 \%$; and wood, $1 \%$ (see Figure 2).

\section{Pre-pandemic MSWM and critical points of potential of infection in Makkah}

The management of MSW has reported multiple challenges, such as the potential risk of virus spread, under the COVID-19 pandemic conditions, including handling, collection, transportation, and disposal. Fears of accumulating plastic waste generated from PPE (i.e., face masks, hand gloves, and plastic sterilization packages) during COVID-19 led to their mixing with MSW (OSHA 2020).

The KSA has launched its most important legislation in the quality-of-life program, according to Kingdom's vision 2030 for sustainable environmental and health objectives, which mainly aims for the best living level for its citizens and residents alike. This culminated in the enactment of the national environment strategy, formalized by the national plan to confront natural disasters, and the establishment of the Saudi Health Council, in order to ensure better health and to reduce the rates of diseases, disability, pandemics, and death, in addition to coordination and integration between health authorities and others to ensure a distinguished public health level.

In addition to the establishment of the Saudi Patient Safety Center (SPSC), which contributed to increasing the percentage of hospitals that achieved the American average for measured patient safety culture from $30 \%$ in 2018 to $60 \%$ in 2019 , the Kingdom topped the list of Arab countries, in terms of the Global Health Security Index, in 2019 and was ranked 47th globally.

During the COVID-19 pandemic, the major priorities for MSW management were (1) ensuring the proper management of SW facilities (i.e., treatment and disposal facilities); (2) strict adjustments to recycling facilities, in order to prevent the potential of infections and cross-contamination; and (3) confirming that the medical waste from quarantine hospitals and centers is treated and managed in a safe manner (ISWA 2020), where it is managed as medical wastes.
Figure 2 A comparison on MSW characterization in Makkah in pre-pandemic and during COVID-19 pandemic conditions

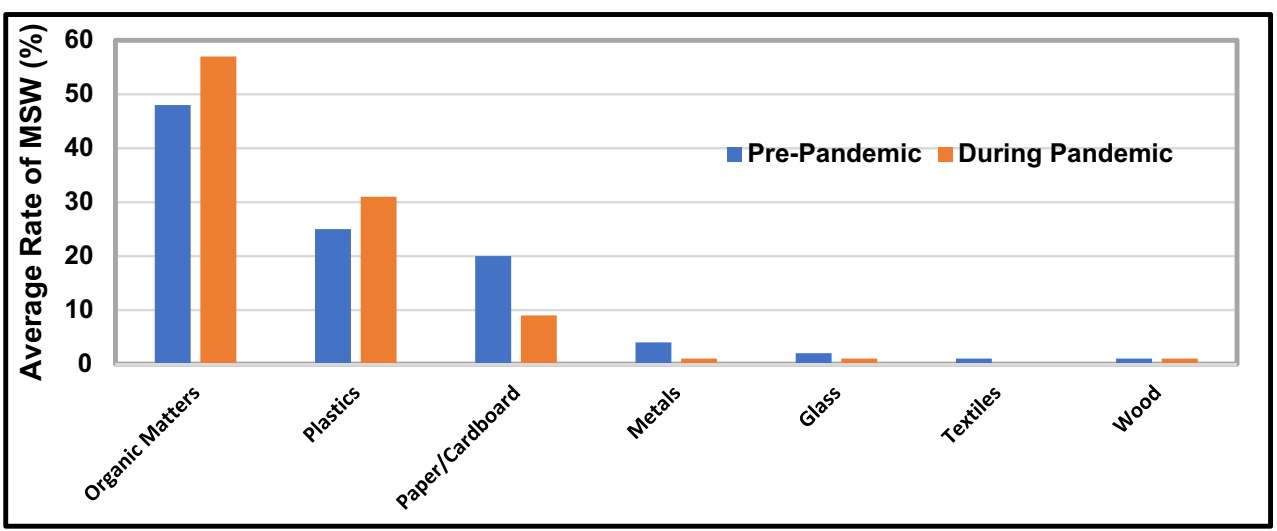


The pre-pandemic procedure of handling, collecting, transporting, and disposing MSW in Makkah can be formalized through (1) the pickers and collectors of MSW; (2) collection of the MSW on the streets by 120-liter bins; (3) evacuation all the plastic bins into metallic containers of 240-liter volume; (4) transportation of the collected MSW from the narrow streets by a specific vehicle to the MSW transfer stations; (5) gathering all the collected MSW at the transfer stations and refilling MSW compactor vehicles, in addition to the compactor vehicles from the central zone and public streets of Makkah; (6) transporting all MSW to the landfill in southwest Makkah (Kaakia landfill); and (7) finally, disposal of the MSW in the landfill (Figure 3).

The system of MSW management in Makkah can be summarized into five major steps: (1) the baseline data of the MSW, in the context of generation rates, quantities of recyclable materials, MSW characterization, and quantities of MSW; (2) the collection procedure of MSW by using the street-to-street method, and during the peak months of Ramadan (Umrah season) and pilgrimage periods for the holy places in Makkah; (3) the transportation of the collected MSW from Makkah and holy places to the MSW transfer stations, then transporting to Kaakia landfill (southwest Makkah); (4) the recovery of MSW, which is not represented in Makkah; and, finally, (5) the disposal of MSW at Kaakia landfill (Figure 4) (Alsebaei 2014).

\section{Impact of the lockdown on the generation of MSW in Makkah}

The lockdown of the residents of Makkah during the COVID19 pandemic has had a direct impact on their lifestyles, in terms of suspension of Umrah, schools, workplaces in all government agencies, sports activities, and gyms. All these life factors have led to lifestyle changes and, consequently, an increase in the organic and plastic components of the generated MSW. In the case of the infected COVID-19 cases, additional health precautionary measures have been implemented, in terms of sorting PPE (e.g., face masks, gloves, and disinfectant) and yellow double-bagging, which is a must, according to Saudi Health Protocol (Figure 5).

The face masks and gloves used as preventive tools against SARS-CoV-2 infection, as advised by all the responsible authorities (MoH 2020), may turn into a new factor for its infectious spread. The improper management of PPE (handling transportation and disposal) may increase exposure to the virus.

In fact, the PPE handling problem should be considered, by all concerned, due to the potential of re-spread of infection of COVID-19 due to the throwing of facemasks and gloves in public streets, in addition to the mixing of non-infected MSW with used face masks and gloves (Figure 6).

In the quarantine hospitals of Makkah, the generated medical waste for COVID-19 was handled, in compliance with the medical protocols issued by the $\mathrm{WHO}$, by placing them in colored bags and marking them with a danger sign. The people who were obliged to quarantine had a private room and bathroom available, such that no one had contact with them, and their waste was placed in sealed bags and sterilized before leaving the room, in order to avoid the spread of infection (MoH 2020).

Concerning the PPE from the commercial food centers of Makkah, some practices were indicated, during COVID-19, related to MSW management and focused on providing specific bins for collecting used face masks, gloves, and disinfectant containers, in order to make sure they were not mixed with the generated MSW (Figure 7).
Figure 3 Traditional MSW collection procedure in Makkah

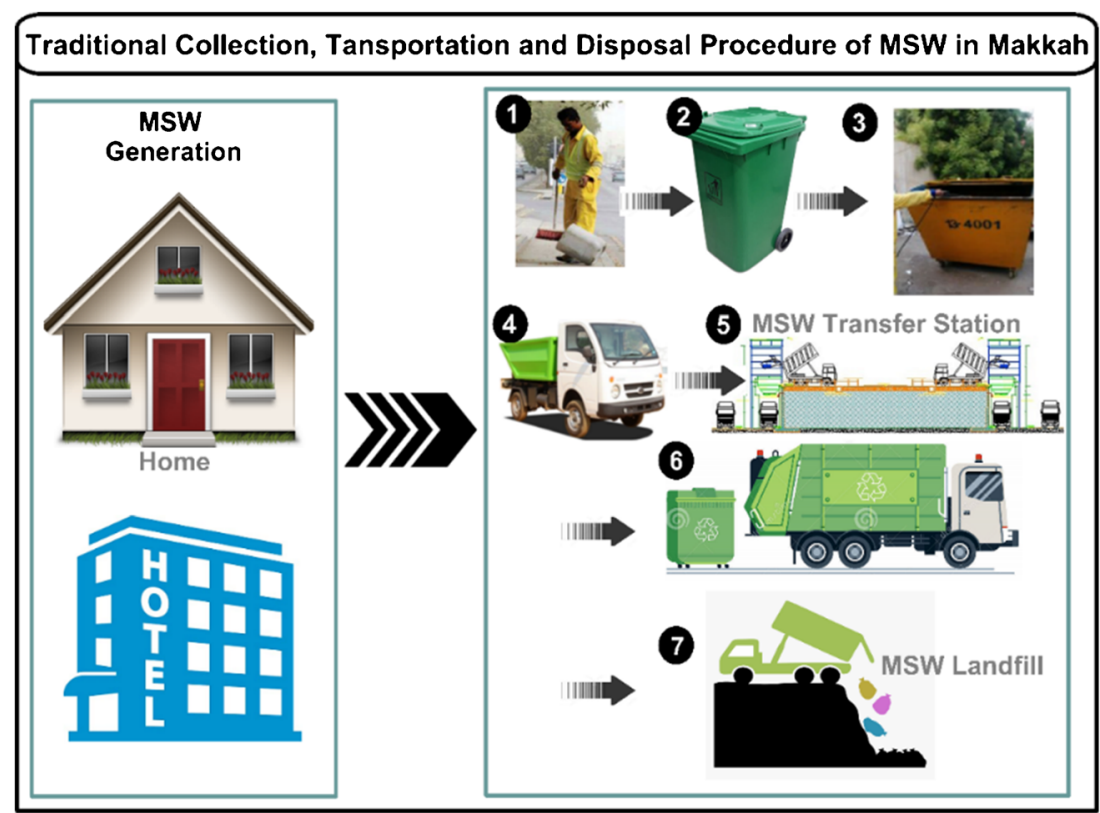




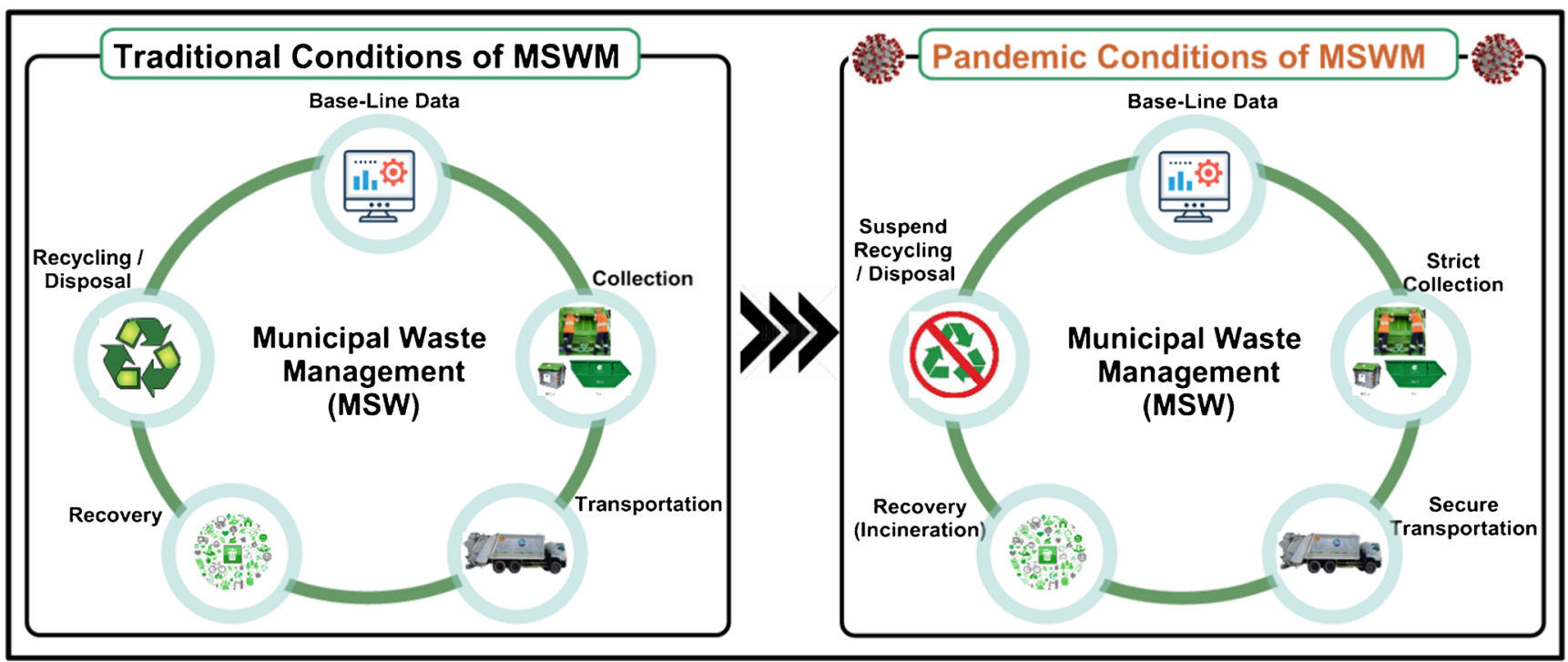

Figure 4 Critical points of MSW management before and during COVID-19 pandemic (under pandemic conditions: strict precautions during collection, transportation, ecovery, disposal, and suspend recycling)

\section{Proposed practices of MSW management during COVID-19 pandemic in Makkah}

The MSW management was affected directly by the routine human activities during the COVID-19 pandemic (Tripathi et al. 2020), in addition to, the potential risk of the SARS$\mathrm{CoV}-2$ infection which may result from the contaminated waste surfaces (Nghiem et al. 2020).

To control the rapid spread of SARS-CoV-2 in outdoor environments, a specific guidance plan for the management of MSW in Makkah should be obeyed, to face the significant challenges for MSW related to the persistence of COVID-19 on different materials.

The elements that can affect the management of MSW during COVID-19 and future pandemics can be summarized as follows: the pickers of MSW (i.e., MSW handlers), plastic bins, metallic containers, specific vehicles, transfer stations, compactor vehicles, and disposal (see Figure 8). These elements may be optimized as follows:
1) Training and increasing the efficiency and specific skills of MSW workers

2) The generated MSW from quarantine sites (homes, hotels), except that which is medical waste-related (e.g., safety face masks, gloves, and other disposable items), should be treated as normal MSW after the necessary measures are taken (e.g., double-bagging, tying properly, and $2 / 3$ of capacity).

3) On-demand MSW services for the specific sites of gardens and bulky waste

4) Periodic cleaning of the streets and plastic and metallic containers

5) The pickers and handlers of MSW during COVID-19 and future pandemics should wear full PPE and take other safety and health measures as precautionary means in their work environment as displayed and ordered in Figure 9.

6) Modulating the frequency of collection of MSW, according to specific needs
Figure 5 Impact of the lockdown during the COVID-19 pandemic on the generated MSW

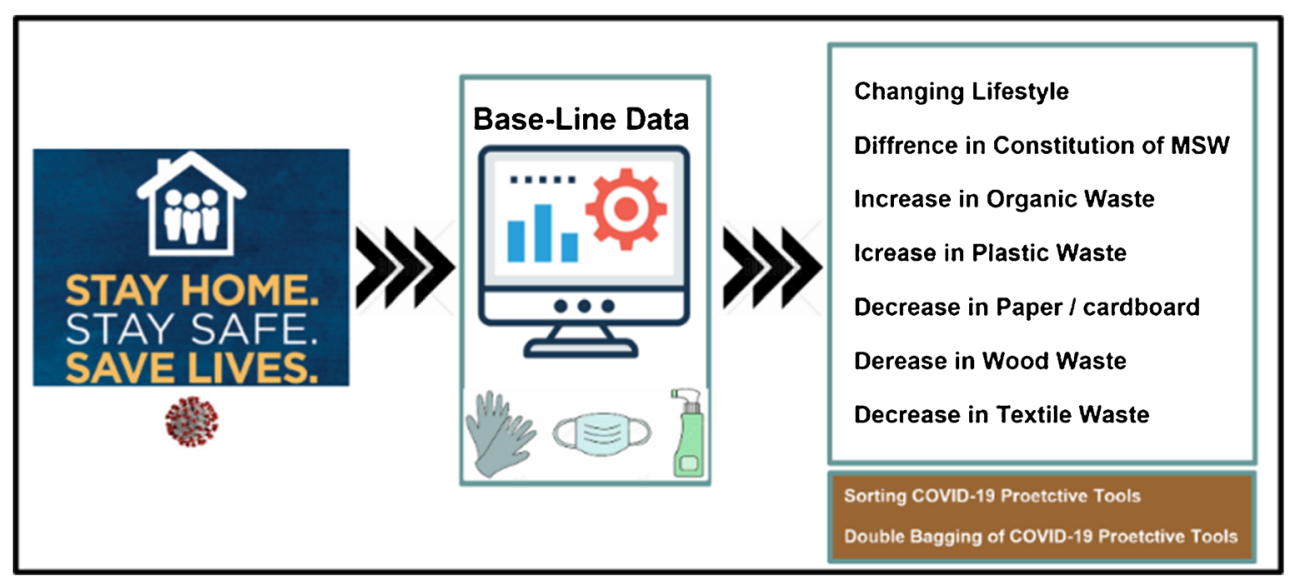


Figure 6 Face masks and gloves on public streets

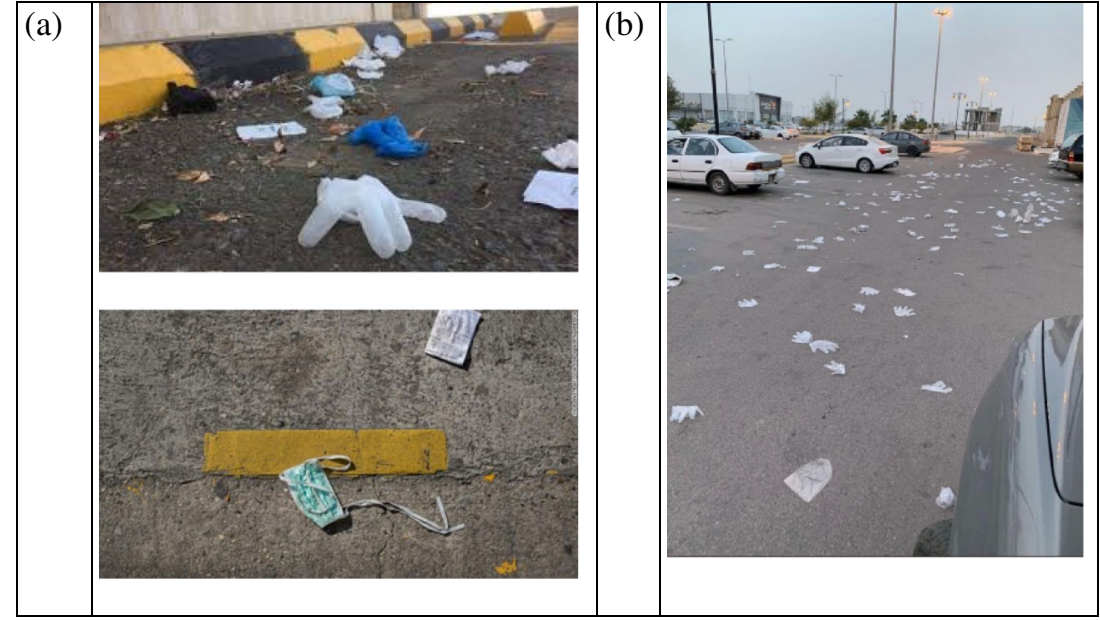

7) Online training for MSW personnel, in order to increase the skills related to health precautions related to MSW management systems

8) Providing disinfectants to the pickers and handlers of MSW throughout the operational time

9) Developing an operational system and designing time gaps for MSW workers, in order to avoid direct contact between workers

10) Periodical medical investigations of MSW pickers, drivers, and workers at disposal sites

11) MSW generated from quarantine sites should be sorted, segregated, and stored separately from the general medical waste at the point of generation.

12) Handling the disinfectants and cleaning solutions as contaminated MSW

13) For commercial centers handling mixed waste (masks, gloves, tissues, and disposable cloths collected with

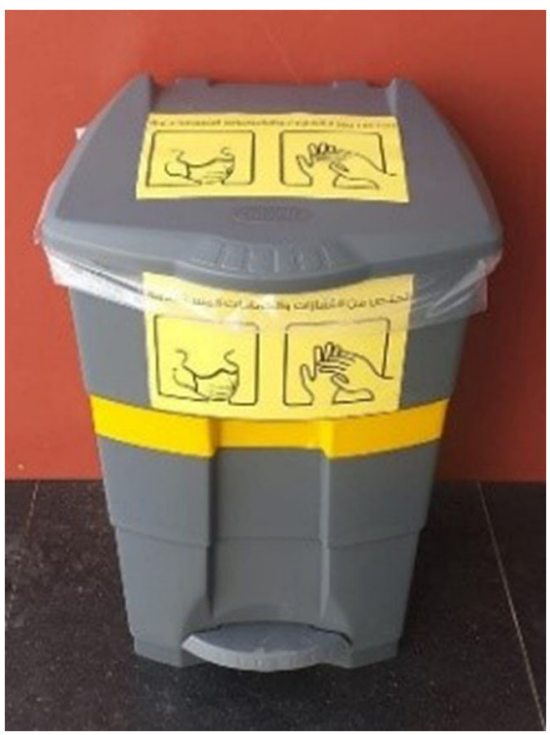

Figure 7 Bin for collecting used PPE from commercial food centers in Makkah
MSW), the bins must have a pedal, two or more sealed bags should be used, and recyclables and biowaste should be combined with mixed waste.

14) Suspension of the MSW transfer stations

15) Encouragement of the utilization of single-use tools within the medical sectors, in order to facilitate better management of the generated wastes

16) Introduction and/or increase of more robust systems for waste segregation, collection, and management, as well as guidance for individuals on how to safely dispose of used medical equipment

17) MSW generated from the quarantine sites (e.g., hospitals, hotels, and schools) should be managed, from collection until disposal, as a medical waste.

18) The suspension of specific vehicles and operating compactor vehicles only

19) Increasing the thickness of sediments that are used as a daily cover for the compacted MSW at the disposal sites (landfill)

\section{Discussion}

MSW may play a great role in the spread of COVID-19 in the outdoor environment, as the disease can be transmitted through contaminated surfaces and hands. There is a high potential risk of the COVID-19 spreading through the contaminated SW surfaces (Nghiem et al. 2020). The potential of infection by the virus through MSW calls for the development of alternative and specific guidance plans, as well as for the updating of policies and guidelines for municipal solid waste management (MSWM), considering MSW workers, handling, collection, transportation, and disposal of the MSW mixed with PPE (e.g., gloves and face masks) during the COVID-19 pandemic and future pandemics, to ensure the safe 
Figure 8 Proposed practices of MSWM in Makkah during COVID-19 pandemic
Collection, Tansportation and Disposal Procedure of MSW During COVID-19 Pandemic in Makkah

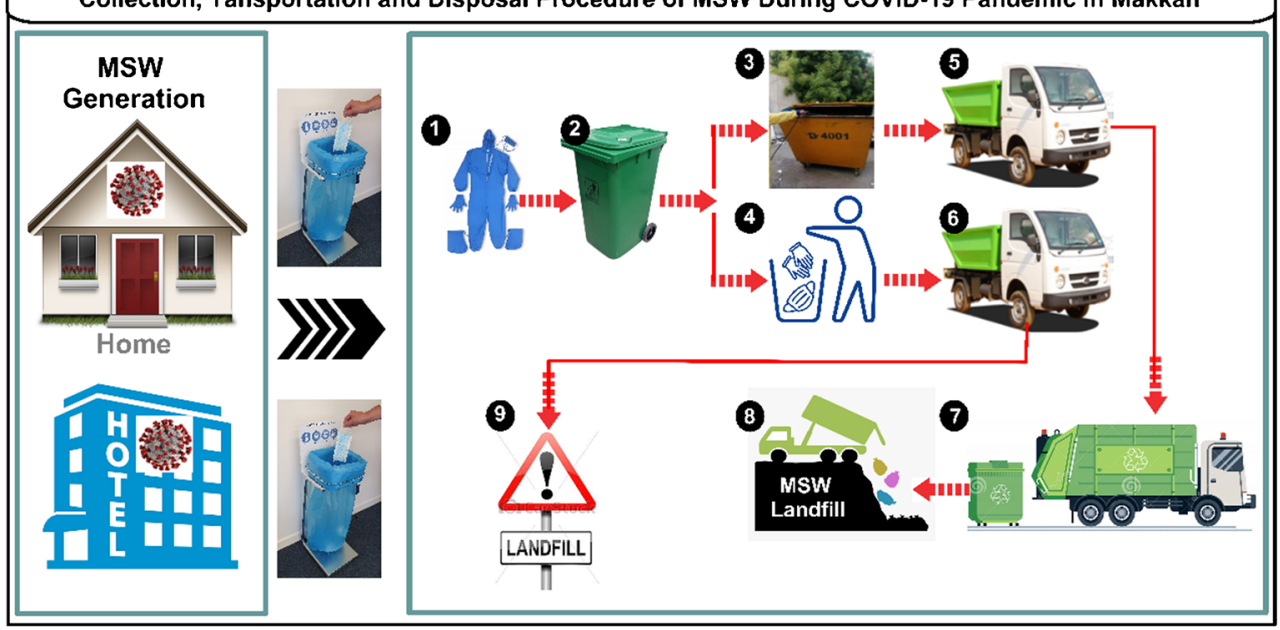

management of MSW and to minimize the related infection risks.

The aerosol survival of related human coronaviruses is relatively high. Approximately $20 \%$ of infectious viruses can remain for 6 days or more in suitable surrounding conditions (Ijaz et al. 1985). Previous studies have suggested that other coronaviruses, such as SARS-CoV, can survive on nonporous surfaces for up to 9-10 days (Casanova et al. 2010; and Chan et al. 2011) and for up to 3-5 days on porous surfaces (Duan et al. 2003). To control the spread of SARS-CoV2, all residents in Makkah were placed on effective lockdown from 23 March to 4 September 2020, as mentioned in Table 1. These control measures impacted the MSW generation, characterization, and management, with a significant increase in medical wastes. The collection and treatment of such waste should be carried out in an effective, timely, and safe manner, to avoid the risk of infection and spread of the disease.

SARS-CoV-2 can survive on different kinds of surfaces for about 3 days, depending on surrounding environmental conditions (DHS Science and Technology Directorate 2020). It can stay for up to 7 days on surgical mask surfaces at $22^{\circ} \mathrm{C}$ and $65 \%$ RH (Chin et al. 2020). SARS-CoV-2 can persist on plastic and metal surfaces for $72 \mathrm{~h}$ at $21-23^{\circ} \mathrm{C}$ and $40 \% \mathrm{RH}$ (van Doremalen et al. 2020). Experimentally, SARS-CoV-2 could survive for more than 2 days on inoculated stainless steel, plastic, ceramics, glass, wood, surgical masks, paper, cotton, and latex gloves (Liu et al. 2021). Changing the routine daily activities of the people during the COVID-19 crisis had direct impact on the MSW management (Tripathi et al. 2020). Therefore, the disposal of personal protective tools (e.g., face masks and gloves) in public streets (Figure 8) and in the metal containers distributed in Makkah may represent a potential source of infection. This leads to pickers collecting such infectious substrates and mixing them with MSW. Such wastes may pose substantial potential threats to public health or the surrounding environment.
SARS-CoV-2 remains detectable at $22^{\circ} \mathrm{C}$ (room temperature) through plaque assay for up to $24 \mathrm{~h}$ on paper currency, for up to $4 \mathrm{~h}$ on clothing, and for up to $96 \mathrm{~h}$ on the skin (Harbourt et al. 2020). In indoor environmental conditions (at room temperature, $24^{\circ} \mathrm{C}$ ), SARS-CoV-2 may persist for hours to days on different kinds of contaminated surfaces (stainless steel, plastic, or nitrile glove). Thus, the contaminated fomites represent a potential risk for virus transmission (Biryukov et al. 2020). Due to the persistence of SARSCoV-2 on the different kinds of surfaces for several hours to few days, the solid wastes may act as a source of infection, especially in indoor environments. Khoo et al. (2021) stated that plastic waste should be properly managed during the COVID-19 pandemic to avoid its adverse effects on the environment, animals, and human health.

The COVID-19 pandemic has posed a major environmental impact, having direct impacts on enhancing the air quality levels around the world due to minimizing the traffic activities during the lockdown, and on the operational tasks of MSW management (ISWA 2020). The sector of MSW has been affected, both directly and indirectly, by the behavior of citizens during the COVID-19 lockdown (minimizing fast foods, maximizing fresh and cooked foods), especially in the city of Makkah, Saudi Arabia. Previously, MSW characterization in Makkah has been investigated across the different districts of Makkah (Osra 2017). Generally, in the city of Makkah, the generation rates of MSW have been decreased, due to suspension of Umrah and partial Hajj performance, the closing of commercial centers and other activities (e.g., schools, universities, hotels, and sporting activities), and the prevention of gathering in public places, during the COVID-19 lockdown. In addition, the rates of MSW components differed, due to such extreme changes of lifestyle, with an increase of organic waste from 48 to $57 \%$, an increase of plastic waste from 25 to $31 \%$, and a decrease of paper/cardboard waste from 20 to $9 \%$ (Figure 2). 


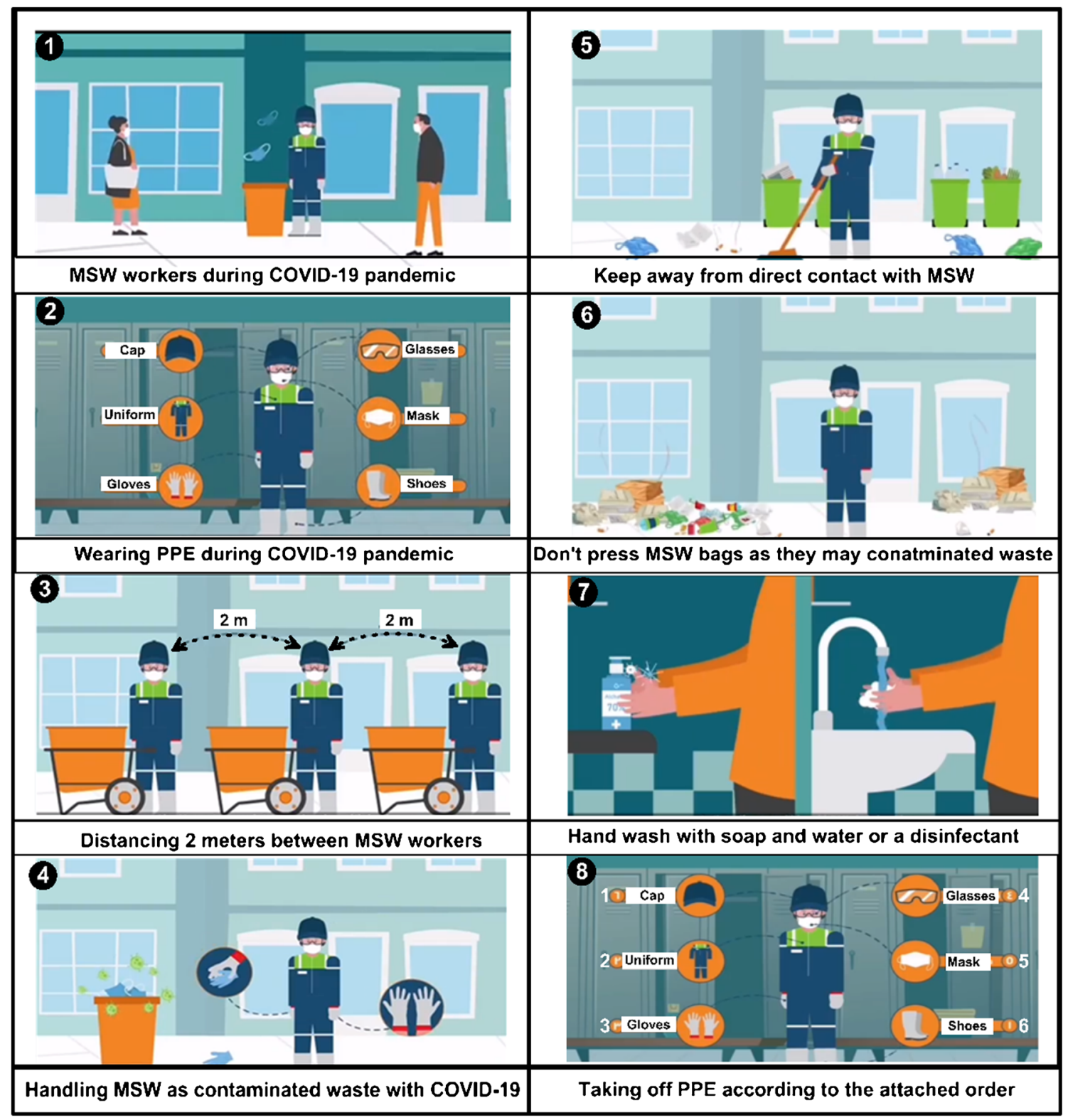

Figure 9 Guidance plan for MSW collection procedure during COVID-19 pandemic

A variety of practices for MSW and mixed waste have been developed globally in response to the COVID-19 pandemic, which can be summarized as follows: the separation of the generated MSW from quarantine sites and its disposal in an isolated cell covered with the layer of lime in Egypt (EEAA 2020); tracking the collection and disposal of household waste, sterilizing containers and public places, and providing scavengers with protective clothing and equipment to protect them from the risk of infection in Morocco (MDS 2020); and the closure of about $42-45 \%$ of MSW sorting centers and $99 \%$ of MSW recycling centers, in order to protect sanitation workers from the risk of spreading infection, in France (MDSDLS 2020). In addition, medical and contaminated waste was collected from centers and hospitals scattered through the Emirates, to be treated according to the highest international and approved local standards (MoHP 2020). From the all above reviews, the problem can be formalized by the mixing of medical waste that may be generated from COVID-19-infected citizens with non-infected MSW; the risk is associated with the handling, collection, transportation, and disposal of these mixed MSW as a pure MSW, which may lead to the spread of COVID-19 infection. The present study suggested that care must be taken when storing the quarantine waste, which should be placed in sealed bags and sterilized before handling in the Kingdom of Saudi Arabia (KSA).

The use of personal protective equipment (PPE) during the COVID-19 pandemic was increased drastically. Some PPE waste is discarded into the environment rather than going to 
incinerators and landfills. Such PPE may carry the causative virus and act as a source of infection. So that, PPE waste represents threats to human health and may facilitate the spread of the disease via different routes of exposure. Therefore, establishment of appropriate guidelines for dealing with the PPE problems related to environment and public health is necessary (Wang et al. 2021). Due to the possibility of SARS-CoV-2 surviving on PPE waste and human skin for few days, a deep investigation into the MSW management system in Makkah was clarified in order to determine the critical points that can lead to the virus spread, starting from the handling task, passing through collection, transportation, and the transfer station, and ending at the disposal sites. The suggested specific guidance plans for MSW management during COVID-19 in Makkah can be summarized in the following points:

1) The MSW workers must be supplied with complete personal protective equipment (PPE), keeping a distance of 2 meters between workers, handling MSW as waste contaminated with SARS-CoV-2, avoiding direct contact with MSW, pressing on MSW bags must be forbidden (as they may contain contaminated waste), periodic hand-washing with soap and disinfectants, and removal of PPE with care.

2) The generated MSW from quarantine sites (households and hotels), except for that which is medical wasterelated (e.g., safety face masks, gloves, and other disposable items), should be treated as normal MSW after the necessary measures are taken (e.g., double-bagging, tying properly, and 2/3 capacity); the specific bulky MSW and that generated from gardens should be collected based on demand, in order to minimize the movements of compactor vehicles on the streets and, consequently, to minimize the potential of infection by COVID-19.

3) Periodic cleaning of the streets and plastic and metallic containers, as well as wearing full PPE and abiding by other safety and health measures as precautionary means in the work environment for MSW pickers and handlers; adapting and modulating the frequency of collection of MSW according to specific needs, and raising the skills of workers, in terms of health precautions related to MSW management systems; providing disinfectants to the pickers and handlers of MSW throughout the operational time; developing an operational system and saving time gaps for MSW workers, in order to avoid direct contact between workers; and the suspension of MSW transfer stations of MSW, in order to minimize the potential of infection by COVID-19

4) Sorting, segregation, and storage of COVID-19 waste (PPE waste, disinfectant, and cleaning solutions), which must be separated from general quarantine sites; periodical medical investigations of the MSW pickers, drivers, and workers at disposal sites, in order to minimize the potential of infection by COVID-19

5) For households, medical waste should be safely handled; gloves and face masks should be sprayed with alcohol, cut into small pieces, collected into $2 / 3$ volume, double-bagged, and the bags should be closed well, in order to be not become mixed with MSW.

6) For the commercial centers, solid waste must be collected separately in a specific bin (Figure 7), while the mixed waste (e.g., masks, gloves, tissues, and disposable cloths) must be collected in bins with a pedal and sealed in two bags.

7) MSW generated from quarantine sites (e.g., hospitals, hotels, and schools) should be managed, from collection until disposal, as a medical waste.

8) Suspension of specific vehicles and operating compactor vehicles only during the pandemic may lower the potential of spread of infection by COVID-19 through the surveyed streets; it is also advised to increase the thickness of sediments used as a daily cover for the compacted MSW at the disposal sites (landfill).

9) The MSW should be collected on a fast-frequent periodical basis, due to the dominant humid and hot weather conditions in Makkah (Khan and Alghafari 2018). Such weather conditions facilitate the quick decomposition of organic matter (which increased to a rate of $57 \%$ of total MSW during the pandemic), thus creating suitable media for the growth and multiplication of infectious agents.

10) Periodical cleaning and disinfection of the compactor vehicles should be applied continually in Makkah, to minimize the suitable media for growth and multiplication of all pathogens through the uncleaned MSW compactors.

\section{Conclusions}

The implementation of control measures, such as the lockdown of citizens, suspending Umrah, performing Hajj with a very limited number of pilgrims, and closing hotels and commercial centers, changed the lifestyle of citizens and, thus, the MSW constitution in Makkah. The present study identified the critical points of the potential of infection in the MSW system during the COVID-19 pandemic in Makkah. Precautionary measures should be implemented, to minimize the potential exposure to MSW which is mixed with the PPE of the public citizens. Experienced and optimum management practices should be applied, aimed at handlers, pickers, transportation, plastic bins, metallic containers, compactor vehicles, MSW transfer station, and disposal sites, to reduce the 
associated risk of infection. A specific guidance plan for MSW management during the COVID-19 pandemic was developed for handlers, pickers, collection, transportation, transfer stations, and MSW disposal. Such a guidance plan may play a great role in controlling the pandemic. MSW management guidelines should be updated periodically, according to the nature and epidemiological pattern of the current and any another future pandemic.

Acknowledgements The authors would like to express their great thanks to the Deanship of Scientific Research at Umm Al-Qura University for supporting this research work by Grant Code: (20-ENG-4-13-0001).

Funding This research was funded by the Deanship of Scientific Research at Umm Al-Qura University, grant number 20-ENG-4-13-0001.

\section{Declarations}

Conflicts of interest The authors declare no conflict of interest.

\section{References}

Alsebaei AF (2014) Solid waste management and recycling during Hajj pilgrimage in Mina. The University of Leeds, School of Civil Engineering, $\mathrm{PhD}$.

Ball S, Taleb MA (2010) Benchmarking waste disposal in the Egyptian hotel industry. Tour Hosp Res 11:1-18

Biryukov J, Boydston JA, Dunning RA, Yeager JJ, Wood S, Reese AL, Ferris A, Miller D, Weaver W, Zeitouni NE, Phillips A, Freeburger D, Hooper I, Ratnesar-Shumate S, Yolitz J, Krause M, Williams G, Dawson DG, Herzog A, Dabisch P, Wahl V, Hevey MC, Altamura LA (2020) Increasing temperature and relative humidity accelerates inactivation of SARS-CoV-2 on surfaces. mSphere 5:e00441-20. https://doi.org/10.1128/mSphere.00441-20

Casanova LM, Jeon S, Rutala WA, Weber DJ, Sobsey MD (2010) Effects of air temperature and relative humidity on coronavirus survival on surfaces. Appl Environ Microbiol 76:2712-2717

Chan KH, Peiris JS, Lam SY, Poon LL, Yuen KY, Seto WH (2011) The effects of temperature and relative humidity on the viability of the SARS coronavirus. Adv Virol 2011:734690

Chin AWH, Chu JTS, Perera MRA, Hui KPY, Yen H, Chan MCW, Peiris M, Poon LLM (2020) Stability of SARS-CoV-2 in different environmental conditions. The Lancet Microbe 1:e10. https://doi. org/10.1016/S2666-5247(20)30003-3

Das AK, Islam MN, Billah MM, Sarker A (2021) COVID-19 and municipal solid waste (MSW) management: a review. Environ Sci Pollut Res 28:28993-29008. https://doi.org/10.1007/s11356-02113914-6

DHS Science and Technology Directorate (2020) Master question list for COVID-19 (caused by SARS-CoV-2) Weekly Report 25 March 2020. Available online: https://www.dhs.gov/sites/default/ files/publications/mq1_sars-cov-2 -cleared-for-public-release 202003 25.pdf. Accessed on 15 April 2020

Duan SM, Zhao XS, Wen RF, Huang JJ, Pi GH, Zhang SX, Han J, Bi SL, Ruan L, Dong XP, SARS Research Team (2003) Stability of SARS coronavirus in human specimens and environment and its sensitivity to heating and UV irradiation. Biomed Environ Sci 16:246-255

EEAA Egyptian Environmental Affairs and Agency (2020) Regulation of municipal solid and medical waste during the pandemic of COVID-
19. Media Reports, 2020. Available online: http://www.eeaa.gov. eg/en-us/laws/wastemanagregulationlaw.aspx. Accessed on 15 Oct 2020

EPA (2002) RCRA waste sampling draft technical guidance planning, implementation, and assessment. EPA530-d-02-002, August 2002. Available online: http://www.epa.gov/osw. Accessed on 20 June 2021

Habeebullah TM, Abd El-Rahim IHA, Morsy EA (2021) Impact of outdoor and indoor meteorological conditions on the COVID-19 transmission in the western region of Saudi Arabia. J Environ Manag 15: 112392. https://doi.org/10.1016/j.jenvman.2021.112392

Hantoko D, Li X, Pariatamby A, Yoshikawa K, Horttanainen M, Yan M (2021) Challenges and practices on waste management and disposal during COVID-19 pandemic. J Environ Manag 286:112140

Harbourt D, Haddow A, Piper A, Bloomfield H, Kearney B, Gibson K, Minogue T (2020) Modeling the stability of severe acute respiratory syndrome coronavirus 2 (SARS-CoV-2) on skin, currency, and clothing. medRxiv 2020:2020.07.01.20144253 Available online: https://www.medrxiv.org/content/medrxiv/early/2020/07/03/2020. 07.01.20144253.full.pdf (accessed on 20 July 2020)

Ijaz MK, Brunner AH, Sattar SA, Nair RC, Johnson-Lussenburg CM (1985) Survival characteristics of airborne human coronavirus 229E. J Gen Virol 66:2743-2748

ISWA (International Solid Waste Association) (2020) COVID-19 response international knowledge sharing on waste management. 2020. Available online: https://www.iswa.org/iswa/covid-19/. Accessed on 30 Oct 2020

Johns Hopkins University Coronavirus Resource Centre (2021) COVID19 dashboard by the Centre for Systems Science and Engineering. Available online: https://eur01.safelinks.protection.outlook.com/?url= https $\% 3 \mathrm{~A} \% 2 \mathrm{~F} \% 2 \mathrm{~F}$ coronavirus.jhu.edu $\% 2 \mathrm{Fmap} . \mathrm{html} \&$ data $=04 \%$ 7C01\%7Cihabdelrahim\%40uqu.edu.sa\%7C3d2439e98386421 c320f08d91c939210\%7C79a057fbb0d544dd8f900bf7151f5c3f\%7C0\% 7 C 0 \% 7C637572242402124721\% 7 CUnknown\% 7 C TWFpbGZsb3d8eyJWIjoiMC4wLjAwMDAiLCJ QIjoiV2luMzIiLCJBTiI6Ik1haWwiLCJXVCI6Mn0\%3D\% $7 \mathrm{C} 1000$ \& sdata=T q W 4 u IeEz56VkJRRuANTtfL \% 2BJPSTBebRruOwTiqflcw\%3D\&reserved=0. Accessed 20 June 2021

Kampf G, Todt D, Pfaender S, Steinmann E (2020) Persistence of coronaviruses on inanimate surfaces and their inactivation with biocidal agents. The Journal of Hospital Infection 2020(104):246-251. https://doi.org/10.1016/j.jhin.2020.01.022

Khan S, Alghafari Y (2018) Temperature, precipitation and relative humidity fluctuation of Makkah Al Mukarramah, Kingdom of Saudi Arabia (1985-2016). Trans Mach Learn Artif Intell 2018(6):42

Khoo KS, Ho LY, Lim HR, Leong HY, Chew KW (2021) Plastic waste associated with the COVID-19 pandemic: crisis or opportunity? J Hazard Mater 417:126108

Klemes JJ, Fan YV, Tan RR, Jiang P (2020) Minimising the present and future plastic waste, energy and environmental footprints related to COVID-19. Renew Sust Energ Rev 127:109883. https://doi.org/10. 1016/j.rser.2020.109883

Kulkarni NB, Anantharama V (2020) Repercussions of COVID-19 pandemic on municipal solid waste management: challenges and opportunities. Sci Total Environ 743:140693

Lai MY, Cheng PK, Lim WW (2005) Survival of severe acute respiratory syndrome coronavirus. Clin Infect Dis 41:e67-e71

Liu Y, Li T, Deng Y, Liu S, Zhang D, Li H, Wang X, Jia L, Han J, Bei Z, Zhou Y, Li L, Li J (2021) Stability of SARS-CoV-2 on environmental surfaces and in human excreta. J Hosp Infect 107:105-107. https://doi.org/10.1016/j.jhin.2020.10.021

Loizia P, Voukkali I, Zorpas AA (2018) Boosting regulations-legislation reliefs regarding environmental management systems (ISO14001EMAS) in the framework of BRAVER - Case study of Cyprus. International Journal of Thermal and Environmental Engineering $17: 19-27$ 
Loizia P, Voukkali I, Zorpas AA, Pedreño JN, Chatziparaskeva G, Inglezakis VJ, Vardopoulos I, Doula M (2021a) Measuring Environmental Performance in the Framework of Waste Strategy Development. Sci Total Environ 753:141974

Loizia P, Voukkali I, Chatziparaskeva G, Pedreño JN, Zorpas AA (2021b) Measuring the level of environmental performance on coastal environment before and during Covid-19 pandemic. A case study from Cyprus, Sustainability 13:2485

Luca F, Cervino G, Matarese M, D’Amico C, Surace G, Paduano V, Fiorillo MT, Moschella A, La Bruna A, Luca Romano G, Laudicella R, Baldari S, Cicciù M (2020) COVID-19 surface persistence: a recent data summary and its importance for medical and dental settings. Int J Environ Res Public Health 17:3132. https://doi. org/10.3390/ijerph17093132

Mazzanti M, Zoboli R (2008) Waste generation, waste disposal and policy effectiveness: evidence on decoupling from the European Union. Resour Conserv Recycl 52:1221-1234

MDS (Ministere De La Sante) (2020) Direction DE L'Epideniologie Et De Lute Contre Les Malladies; Royaume Du Maroc; Epidémie du COVID-19 au Maroc. Available online: https://www.sante.gov.ma/ Pages/ADM_Centrale/DELM.aspx. Accessed on 15 Nov 2020

MDSDLS (Ministere Des Solidarites Et De La Sante) (2020) ContactCOVID et SI-DEP, les outils numériques du dépistage COVID-19, France. Available online: https://solidarites-sante.gouv.fr/soins-etmaladies/maladies/maladies-infectieuses/coronavirus/tout-savoirsur-la-covid-19/article/contact-covid-et-si-dep-les-outilsnumeriques-du-depistage-covid-19. Accessed on 30 Oct 2020

$\mathrm{MoH}$ (Saudi Ministry of Health) (2020) Periodic reports and guidelines for facing COVID-19 pandemic. Available online: https://www. moh.gov.sa/en/Ministry/MediaCenter/News/Pages/News-2020-0317-001.aspx. Accessed on 20 April 2020

MoHP (Ministry of Health and Prevention, United Arab Emirates) (2020) The important preventive actions against corona virus (COVID -19), United Arab Emirates. Available online: https://www.mohap.gov. ae/en/MediaCenter/Pages/videos.aspx?videoId=595. Accessed on 18 April 2020

Mol MPG, Caldas S (2020) Can the human coronavirus epidemic also spread through solid waste? Waste Manag Res 38:485-486. https:// doi.org/10.1177/0734242X20918312

MoM (Saudi Ministry of Media) (2020) KSA faces COVID-19; A report summarizing the government's efforts in combating the spread of the COVID-19. First Edition April. Available online: https://media. gov.sa/en/news/2623. Accessed on 10 Sept 2020

Nghiem LD, Morgan B, Donner E, Short MD (2020) The COVID-19 pandemic: considerations for the waste and wastewater services sector. Case Studies in Chemical and Environmental Engineering 1: 100006. https://doi.org/10.1016/j.cscee

Occupational Safety and Health Administration (OSHA) (2020) Guidance on preparing workplaces for COVID-19. Available online: https://www.osha.gov/sites/default/files/publications/ OSHA3990.pdf. Accessed on 10 Nov 2020
Osra F (2017) Optimizing the suitable site(S) for landfill by multi-criteria decision and investigating biogasification potential of the waste in Makkah, Saudi Arabia. Ph.D. Thesis, Institute of Graduate Studies in Science and Engineering, Istanbul University, Istanbul, Turkey

Saadat S, Rawtani D, Mustansar C (2020) Environmental perspective of COVID-19. Sci Total Environ 728:1-6. https://doi.org/10.1016/j. scitotenv

Sizun J, Yu MW, Talbot PJ (2000) Survival of human coronaviruses $229 \mathrm{E}$ and OC43 in suspension and after drying on surfaces: a possible source of hospital-acquired infections. J Hosp Infect 46:55-60

Smart Waste Report European Union (2020) COVID-19 and municipal waste management 2020. Available online: https://www. interregeurope.eu/smartwaste/news/news-article/8127/. Accessed on 15 Oct 2020

Tripathi A, Tyagi VK, Vivekanand V, Bose P, Suthar S (2020) Challenges, opportunities and progress in solid waste management during COVID-19 pandemic. Case Studies in Chemical and Environmental Engineering 2:100060

van Doremalen N, Bushmaker T, Morris DH, Holbrook MG, Gamble A, Williamson BN, Tamin A, Harcourt JL, Thornburg NJ, Gerber SI et al (2020) Aerosol and surface stability of SARS-CoV-2 as compared with SARS-CoV-1. N Engl J Med 16(382):1564-1567

Wang Z, Guy C, Ng KTW, An CA (2021) New challenge for the management and disposal of personal protective equipment waste during the COVID-19 pandemic. Sustainability 13:7034. https://doi.org/10. 3390/su13137034

Warnes SL, Little ZR, Keevil CW (2015) Human coronavirus 229E remains infectious on common touch surface materials. mBio 6: e01697

Yousefi M, Oskoei V, Jafari AJ, Farzadkia M, Firooz MH, Abdollahinejad B, Torkashvand J (2021) Municipal solid waste management during COVID-19 pandemic: effects and repercussions. Environ Sci Pollut Res 28:32200-32209. https://doi.org/10. 1007/s11356-021-14214-9

Zand DA, Heir VA (2020) Emerging challenges in urban waste management in Tehran, Iran during the COVID-19 pandemic. Resour Conserv Recycl 162:105051

Zhu N, Zhang D, Wang W, Li X, Yang B, Song J, Zhao X, Huang B, Shi W, Lu R, Niu P, Zhan F, Ma X, Wang D, Xu W, Wu G, Gao GF, Tan W, China Novel Coronavirus Investigating and Research Team (2020) A novel coronavirus from patients with pneumonia in China; 2019. N Engl J Med 382:727-733

Zorpas AA (2020) Strategy development in the framework of waste management. Sci Total Environ 716:137088

Zorpas AA, Voukkali I, Loizia P (2014) The impact of tourist sector in the waste management plans. Desalin Water Treat 56:1141-1149

Zorpas AA, Lasaridi K, Voukkali I, Loizia P, Chroni C (2015) Household waste compositional analysis variation from insular communities in the framework of waste prevention strategy plans. Waste Manag 38: 3-11. https://doi.org/10.1016/J.WASMAN.2015.01.030 